\title{
Estado, sociedade e políticas de trabalho e emprego voltadas para os jovens no Brasil
}

\author{
Maisa Bruna de Almeida Nunes \\ Universidade Federal do Amazonas (UFAM)
}

\author{
Cristiane Bonfim Fernandez \\ Universidade Federal do Amazonas (UFAM)
}

\section{Estado, sociedade e políticas de trabalho e emprego voltadas para os jovens no Brasil}

Resumo: O artigo desenvolve uma reflexão sobre Estado, sociedade e políticas públicas com o objeto de compreender a forma como são conduzidas as políticas de trabalho e emprego para os jovens brasileiros, indicando seus avanços, entraves e desafios. O estudo evidencia que a relação Estado-sociedade constitui um desafio na contemporaneidade, principalmente em virtude da relação dialética no trato das políticas públicas brasileiras. Por fim, constata alguns avanços que devem ser potencializados no sentido de efetivar o direito ao trabalho com qualidade para o público juvenil.

Palavras-chave: Estado. Sociedade. Políticas Públicas. Juventude.

\section{State, Society and Labor and Employment Policies Aimed at Youths in Brazil}

Abstract: The article reflects on the state, society and public policies to understand how labor and employment policies are aimed at Brazilian youths, indicating their advances, constraints and challenges. The study reveals the contemporary challenge to the relationship of state and society, which in Brazil is mainly due to the dialectical relationship in handling public policies. It identifies some advances that should be supported to realize the right of youths to quality work.

Keywords: State. Society. Public Policies. Youth. 


\section{Introdução}

Analisar a relação dialética entre Estado e sociedade na condução das políticas públicas representa um desafio, principalmente em virtude da complexidade que caracteriza esta questão e do envolvimento de interesses conflitantes. As políticas públicas constituem relações tanto de reciprocidade como de antagonismo que permitem a luta política em busca da conquista e efetivação da cidadania. Ao tratar, mais especificamente, das políticas de trabalho e emprego voltadas aos jovens no Brasil, a análise torna-se ainda mais desafiadora, pois surgem vários elementos que são determinantes para sua formulação e implementação na sociedade brasileira. Isto pode ser verificado quando consideramos a globalização da economia em que o Estado se torna pequeno frente a atores institucionais que detêm maior poder político e econômico, além de uma sociedade civil cada vez mais heterogênea e com demandas diversificadas.

Este artigo tem por objetivo fomentar uma reflexão sobre Estado, sociedade e políticas públicas com o intuito de compreender de que forma são conduzidas as políticas de trabalho e emprego direcionadas a juventude no Brasil, identificando seus avanços, entraves e desafios que perpassam a efetivação do direito ao trabalho. Para fundamentar esta reflexão foi realizada uma pesquisa bibliográfica cujas principais referências teóricas são: Corrochano (2011), Gonzalez (2009), Pereira (2009), Serafim (2011), Pochmann (2000), Souza (2007). O texto divide-se em dois tópicos: o primeiro aborda a relação Estado-sociedade na constituição das políticas públicas e o segundo trata a condução das políticas de trabalho e emprego voltadas para os jovens no Brasil.

\section{Relação Estado-sociedade na constituição das políticas públicas}

As questões que permeiam a relação Estado-sociedade são complexas, pois envolvem interesses conflitantes e muitas vezes contraditórios. Existem distintas interpretações quando se refere à relação Estadosociedade, dentre estas, segundo Serafim (2011), destacam-se três: a primeira concebe o Estado como o centro das relações entre Estado e sociedade, denominando-se Estadocêntrica, ou seja, o Estado teria certa autonomia em relação à sociedade. As decisões tomadas no âmbito estatal seriam repassadas para a sociedade, por meio das políticas públicas, respeitando ou não suas demandas e necessidades sociais. A segunda entende a relação Estado-sociedade como sociocêntrica, em que o Estado estaria a serviço da sociedade. A máquina do Estado deveria estar sempre atenta às demandas e necessidades sociais. Os diferentes grupos (classes sociais) seriam determinantes na escolha das políticas desenvolvidas pelo Estado. A terceira trás uma visão mista ou intermediária, pois tanto afasta o racionalismo economicista ou social da primeira visão como também nega a sociedade submetida a um Estado que se encontra refém de uma minoria. Essa visão leva em consideração os fatores internos (Estado) e externos (sociedade) e busca apreender a sociedade como um conjunto de relações tanto interdependentes como dependentes.

Nesse sentido, a compreensão de política pública está relacionada ao modo de se conceber o Estado. Conforme Serafim (2011, p. 315):

A forma com que se entende uma política pública está diretamente relacionada com a percepção que se tem de Estado. Frequentemente, compreende-se a política pública como uma ação ou conjunto de ações por meio das quais o Estado interfere na realidade, geralmente com o objetivo de atacar um problema. Essa definição se mostra um tanto simplista, uma vez que trata o Estado como um ator que opera de forma autônoma e beneficia a sociedade como um todo através de suas ações.

Para Souza (2007) a definição mais conhecida sobre políticas públicas continua sendo a de Laswell, para quem as decisões e análises sobre política pública precisam responder às seguintes questões: quem ganha o quê, por quê e que diferença faz. A definição mais clássica pode ser atribuída a Lowi apud Rezende (2004, p. 13), que entende a política pública como "regra formulada por alguma autoridade governamental que expressa uma intenção de influenciar, alterar, regular, o comportamento individual ou coletivo através do uso de sanções positivas ou negativas". Assim sendo, apreende-se que as políticas públicas não são descontextualizadas e sem finalidade, mas repercutem na economia e na sociedade que são também afetadas por elas. Por esta razão qualquer teoria da política pública precisa necessariamente explicar as inter-relações entre Estado, política, economia e sociedade. De acordo com Pereira (2009, p. 69), pode-se compreender a política pública como:

o campo do conhecimento que busca, ao mesmo tempo, colocar o ‘governo em ação’ e/ou analisar essa ação (variável independente) e, quando necessário, propor mudanças no rumo ou curso dessas ações (variável dependente). A formulação de políticas públicas constitui-se no estágio em que governos democráticos 
traduzem seus propósitos e plataformas eleitorais em programas e ações, que produzirão resultados ou mudanças no mundo real.

A política pública também está relacionada a conflitos de interesses e é resultado de decisões que visam administrar esses conflitos. Além disso, não significa tão somente ação: "Pode ser também não-ação intencional de uma autoridade pública frente a um problema ou responsabilidade de sua competência. Daí a sucinta definição de Thomas Dye (1972): política pública é o que o governo escolhe ou não fazer” (PEREIRA, 2009, p. 97).

Segundo Souza (2007), o processo de definição das políticas públicas, sociedades e Estados complexos, como os constituídos no mundo moderno, estão mais próximos da perspectiva teórica daqueles que defendem uma autonomia relativa do Estado, o que faz com que este tenha um espaço próprio de atuação, embora permeado de influências externas e internas. Essa autonomia relativa gera determinadas capacidades as quais, por sua vez, criam as condições para a implementação de objetivos de políticas públicas. O papel das instituições/regras na decisão é fundamental na formulação das políticas públicas:

As instituições tornam o curso de certas políticas mais fáceis do que outras, (...) as instituições e suas regras redefinem as alternativas políticas e mudam a posição relativa dos atores. Em geral, instituições são associadas à inércia, mas muita política pública é formulada e implementada. Assim, a teoria neo-institucionalista nos ajuda a entender que não são só os indivíduos ou grupos que têm força relevante influenciam as políticas públicas, mas também as regras formais e informais que regem as instituições (SOUZA, 2007, p. 81-82).

Os estudos sobre concepções de política pública não possuem unanimidade, existem diferentes e conflituosas interpretações. Mas neste trabalho ressaltamos duas: a que privilegia o Estado como produtor exclusivo de política pública, a ponto de identificar o termo público como sinônimo do termo estatal; e a que privilegia a relação dialeticamente contraditória entre Estado e sociedade. Esta última interpretação leva em consideração as diversas circunstâncias que determinam a concepção das políticas públicas, ou seja, as questões estruturais, políticas, econômicas e casuais que perpassam a relação Estado/Sociedade. Com isso, é possível compreender os interesses e a visão de cada ator político envolvido nesse processo e seu objetivo no atendimento a determinada demanda. Desta forma, "é justamente por ser conflituosa (e contraditória), que a política permite a formação de contra poderes em busca de ganhos para a comunidade e de ampliação da cidadania" (PEREIRA, 2009, p. 91).

A política pública se refere a uma política cuja principal característica é o fato de ser pública, isto é, de todos, e não por ser estatal (do Estado) ou coletiva (de grupos particulares da sociedade) e muito menos individual. Conforme Pereira (2009, p. 95-96), o caráter público das políticas públicas ocorre pelo fato destas significarem um conjunto de decisões e ações que resultam, ao mesmo tempo, de ingerências do Estado e da Sociedade, apresentando as seguintes características:

a) Constitui um marco ou linha de orientação para a ação pública, sob a responsabilidade de uma autoridade também pública (...) sob o controle da sociedade. b) Visa concretizar direitos sociais conquistados pela sociedade e incorporados nas leis. Ou melhor, os direitos sociais declarados e garantidos nas leis (...) só têm aplicabilidade por meio de políticas públicas, as quais, por sua vez, operacionalizam-se por meio de programas, projetos e serviços. c) Guia-se pelo princípio do interesse comum, ou público, e da soberania popular, e não do interesse particular e da soberania dos governantes. d) Deve visar à satisfação das necessidades sociais e não da rentabilidade econômica privada, ou, (...) das necessidades do capital.

Nesta lógica, a política pública é concebida como uma estratégia de ação pensada, planejada e avaliada a partir de uma racionalidade coletiva em que tanto o Estado como a sociedade desempenham papeis ativos, envolvendo diferentes atores (governamentais e não-governamentais) por meio de demandas, suportes ou apoios e mediante o controle democrático. Portanto, o estudo da política pública é também o estudo do Estado em ação nas suas permanentes relações de reciprocidade e antagonismo com a sociedade, a qual constitui o espaço privilegiado das classes sociais (PEREIRA, 2009).

Por fim, a relação entre Estado e sociedade, o nível de distância ou proximidade destes e as formas de utilização ou não dos canais de comunicação entre diferentes grupos da sociedade e órgãos públicos (que refletem e incorporam fatores culturais) terminam por estabelecer contornos próprios da constituição de políticas públicas pensadas para uma sociedade. Fica evidente que as formas de organização, o poder de pressão e articulação de diferentes grupos sociais no processo de estabelecimento e reivindicação de demandas são fatores fundamentais na conquista de novos e mais amplos direitos sociais, incorporados ao exercício da cidadania (HOFLING, 2001). 


\section{Condução das políticas de trabalho e emprego voltadas para os jovens no Brasil}

Compreender a juventude a partir de sua construção social, cultural e histórica, procurando refletir sobre suas especificidades e aproximações é fundamental quando pensamos a constituição das políticas de trabalho e emprego direcionadas aos jovens no Brasil. Desta forma, é preciso reconhecer a importância da relação juventude e trabalho buscando compreender o diálogo entre a juventude e as atuais políticas e ações de inserção dos jovens no mundo do trabalho.

A relação jovem e trabalho ganhou visibilidade recentemente, sobretudo, a partir dos anos 1990 devido ao significativo aumento populacional dos jovens (denominada onda jovem) em um contexto de profundas transformações no mundo do trabalho, desencadeadas a partir da década de 1970. Uma das consequências das mudanças no mundo do trabalho foi o desemprego juvenil, que não se limitou aos jovens, mas os afetou intensamente em termos de oportunidades de trabalho. Em razão da existência da mão de obra excedente, muitas vezes os jovens encontram-se em desvantagem, assumindo funções inferiores, com menores salários e jornadas mais intensas, revelando a precarização a que está submetido o trabalho entre os jovens, marcando especialmente o acesso ao primeiro emprego (POCHMANN, 2000).

Segundo a Organização Internacional do Trabalho (OIT) (apud Corrochano 2011, p. 51), o período entre 1992 e 2006 foi marcado pelo aumento da taxa de desocupação entre jovens e adultos, no entanto, os índices de desemprego cresceram mais para os jovens: "entre os adultos acima de 25 anos passou de $4,3 \%$ para 5,6\%, enquanto entre os jovens cresceu de 11,9\% para $18 \%$. Em 2006, enquanto a taxa geral de desemprego (...) era de $8,4 \%$ e para os adultos chegava a $5,6 \%$, para os jovens entre 15 e 24 anos alcançava $17,8 \%$, ou seja, era 3,2 vezes superior à dos adultos". Ainda em 2006, cerca de 3,9 milhões jovens encontravam-se desempregados. Apesar disso, segundo dados da OIT (2013), o Brasil conseguiu diminuir a taxa de desemprego entre os jovens, no entanto, em 2011 ainda chegava a 15,3\%.

Assim como a temática da juventude começa a ganhar

\section{A juventude constitui uma} complexidade de situações que se expressam de diferentes

\section{formas na vida de cada jovem.}

Por isso, não é recomendável pensar em uma trajetória linear quando o assunto é educação e trabalho, cada

jovem seguirá seu percurso conforme os determinantes sociais e culturais que está inserido. Portanto, é preciso que as políticas para a juventude sejam pensadas

nesse sentido, respeitando as especificidades desse segmento, aliando suas necessidades a seus direitos. projeção e complexidade na agenda pública nacional e internacional, no âmbito da política pública de trabalho isso também ocorre, sobretudo quando o jovem passa a ganhar relevância como público-alvo, pois começa a entrar nas estatísticas de desemprego, ameaçando a desagregação do tecido social, revelando o tamanho da pobreza estrutural e passando a figurar no quadro de preocupação de governos e organismos internacionais. No Brasil foi possível observar as diversas transformações no mercado de trabalho, inclusive nas próprias relações de trabalho. Os ajustes ocorreram por meio da terceirização, do crescimento de emprego rotativo e de baixa qualidade, bem como pela intensificação da informalização. Tais ajustes agravaram ainda mais os fatores que já relegavam especificidade e complexidade aos problemas ligados às políticas públicas de trabalho (VELASCO, 2012).

Na primeira década do século 21, importantes avanços ocorreram no âmbito das políticas públicas voltadas para a juventude no Brasil, especialmente na área do trabalho. Em 2005 foi instituída a Política Nacional da Juventude e criada a Secretaria Nacional de Juventude (SNJ), o Conselho Nacional de Juventude (CONJUVE) e o Programa Nacional de Inclusão de Jovens (PROJOVEM). Inicialmente os programas de formação e qualificação profissional tinham como público alvo os jovens de 16 a 24 anos. A partir de 2003 pelo menos três grandes programas direcionados para a geração de trabalho e renda foram criados: o Programa Nacional de Estímulo ao Primeiro Emprego para os Jovens (PNPE); o Projeto Agente Jovem de Desenvolvimento Social e Humano; e o Programa Escola de Fábrica. Em 2007 estes programas passaram por um conjunto de mudanças que foram mobilizados por avaliações e resultados pouco significativos que culminaram em várias reformulações, inclusive na faixa etária do público alvo, que passou a ser de 
15 a 29 anos. Assim, a busca por uma maior integralização dos programas e projetos direcionados aos jovens orientou a atuação da Secretaria Nacional da Juventude para o lançamento do novo Projovem (BRASIL, 2014a).

Em 2004 foi criado o Departamento de Políticas de Trabalho e Emprego para a Juventude (DPJ), no âmbito do Ministério do Trabalho e Emprego, com o objetivo de atuar na promoção de mais e melhores oportunidades de trabalho, emprego e geração de renda para os jovens. Dentre os programas, ações e iniciativas voltadas para o público juvenil destacam-se: a) o ProJovem Trabalhador, que visa capacitar jovens para o mercado de trabalho em ocupações alternativas geradoras de renda. Tem como público alvo os jovens com idade entre 18 e 29 anos que estejam em situação de desemprego, sejam membros de famílias com renda mensal per capita de até um salário mínimo, tenham concluído ou estejam cursando o ensino fundamental ou médio, e não sejam universitários; b) a Lei do Estágio n. 11.788/2008 que dispõe sobre o estágio de estudantes e representou uma evolução na política pública de emprego para jovens no Brasil ao reconhecer o estágio como um vínculo educativoprofissionalizante, supervisionado e desenvolvido como parte do projeto pedagógico; e por fim, c) a Aprendizagem que estabelece que todas as empresas de médio e grande porte estão obrigadas a contratarem adolescentes e jovens entre 14 e 24 anos. Trata-se de um contrato especial de trabalho por tempo determinado, de no máximo dois anos. Os jovens beneficiários são contratados por empresas como aprendizes de ofício, e ao mesmo tempo, são matriculados em cursos de aprendizagem (BRASIL, 2014a).

Atualmente as políticas de trabalho direcionadas aos jovens no Brasil são conduzidas a partir de ações voltadas à qualificação profissional e a intermediação de mão de obra, buscando contribuir para o reconhecimento e valorização dos jovens como pessoa mediante sua autonomia e o exercício de seus direitos e de sua liberdade; enquanto cidadão, consciente de seu protagonismo, efetivando sua participação no aprimoramento da democracia e na defesa dos direitos civis, políticos e sociais; e enquanto trabalhador, qualificado social e profissionalmente para a inserção cidadã no mundo social e do trabalho. Além disso, as ações públicas referentes ao trabalho estiveram, e estão, em grande parte, concentradas na elevação da escolaridade (BRASIL, 2014a). Entre as iniciativas recentes encontra-se o Programa Nacional de Acesso ao Ensino Técnico e Emprego (PRONATEC), criado pelo Governo Federal em 2011 no âmbito do Ministério da Educação (MEC) cujo objetivo é a ampliação da oferta de cursos de educação profissional e tecnológica. São oferecidos cursos gratuitos nas escolas públicas federais, estaduais e municipais nas unidades de ensino do SENAI, do SENAC, do SENAR e do SENAT ${ }^{1}$, em instituições privadas de ensino superior e de educação profissional técnica de nível médio (BRASIL, 2014).

Sabemos que aprimorar a habilidade dos jovens não é condição suficiente para lhes garantir um trabalho digno e de qualidade. Em um contexto de desemprego em alta, a oferta de formação profissional pode ser essencialmente compensatória, pois na melhor das hipóteses deve apenas diminuir a desigualdade interna ao mercado de trabalho se for dirigida aos jovens de menor "empregabilidade"2 (GONZALEZ, 2009). No entanto, as iniciativas voltadas para a qualificação e aprimoramento dos jovens também são necessárias, pois podem ser um diferencial importante para a inserção e permanência dos jovens no mercado de trabalho. Para tanto, é preciso que sejam construídas ações específicas para a juventude em relação ao trabalho que possibilitem de fato uma mudança nos rumos das políticas públicas de educação, trabalho e renda dirigidas aos jovens brasileiros.

Segundo Velasco (2012), os programas de formação e qualificação profissional voltados para os jovens são vistos como exemplos de focalização das políticas públicas para o trabalho. Desta forma, um dos entraves ancora-se no pensamento predominante de que estas ações alcançam apenas o nível microeconômico, com forte tendência a se concentrar somente sobre a oferta e demanda de trabalho, confirmando a crença de que o próprio funcionamento do mercado de trabalho é capaz por si só de gerar vagas. No entanto, esta mesma qualificação acaba por ser legitimada, pois se apresenta como um dos requisitos essenciais ao processo reestruturação produtiva, postulada como um elemento fundamental da chamada empregabilidade.

Cabe contextualizar que nos países centrais o período chamado de 30 anos gloriosos do capitalismo (a partir do segundo pós-guerra) foi caracterizado por elevadas taxas de emprego e lucratividade do setor produtivo, atribuído em grande parte ao aumento expressivo da participação do Estado na sociedade, por meio da construção de sistemas de proteção social. Todavia, esse cenário se alterou profundamente a partir dos anos 1970 e aos poucos foi se consolidando um novo padrão de acumulação capitalista, que implicou novas regras e valores acerca do trabalho denominado por Harvey (1992) como "Regime de Acumulação Flexível"3. Esse modelo flexível de gestão e de organização do trabalho gerou um novo arranjo societal passando a comportar novas formas instáveis e precárias de trabalho, criando a concepção de um trabalhador flexível (SILVA, 2012).

Diante desse contexto, Velasco (2012, p. 254-255) argumenta que:

Desse modo, manifesta-se uma tensa e contraditória relação, pois, ao mesmo tempo em que pretende criar condições favoráveis à inserção do jovem no mercado de trabalho, tende à individualização (...). O risco, então, é que os programas, valendo-se, no campo ideológico, de um conteúdo que remete ao indivíduo o êxito/fracasso ocupacional, levado à órbita de seu próprio comportamento, retirem-no, portanto, da ordem 
e responsabilidade públicas. Por isso, o conteúdo formativo vale-se da difusão de argumentos que ressaltam o papel do próprio jovem tanto de inserção em atividades solidárias como de planejamento e busca do próprio emprego.

Para Araújo (2011, p. 228) tais programas possuem uma atuação limitada diante da atual realidade e são incapazes de solucionar questões históricas presentes na estrutura da sociedade capitalista, responsáveis pelo processo de exclusão social de muitos jovens brasileiros. As atuais políticas de trabalho direcionadas aos jovens, mesmo sendo limitadas, buscam ser inovadoras, pois acionam "um conjunto de dispositivos voltados para a mudança das precárias condições de jovens que foram excluídos historicamente do sistema educacional e do mercado de trabalho".

Apesar desses entraves que dificultam condução das políticas de trabalho e emprego para os jovens brasileiros, segundo dados do Ministério do Trabalho e Emprego (MTE), desde 2005 cerca de 1,9 milhão jovens foram qualificados. Desse total, aproximadamente 1,5 milhão foram inseridos no mercado de trabalho. Através do Projovem Trabalhador, de 2007 para cá, foram qualificados pelo menos 650 mil e inseridos 200 mil. Especificamente pela Aprendizagem, um total de 1,3 milhão de jovens foram alcançados pelo programa, sendo que de janeiro a maio de 2013 foram mais de 142 mil jovens admitidos em mais de 85 mil ocupações administrativas (BRASIL, 2014a). Os dados demonstram que apesar da atuação limitada das atuais políticas de trabalho, em virtude do contexto histórico, econômico e social brasileiro, ainda assim foi possível o alcance de mudanças significativas rumo à efetivação do direito ao trabalho para a juventude.

Para além desses dados, é essencial o desenvolvimento e a implementação de novos paradigmas sobre o trabalho, que devem ser construídos coletivamente, pois se trata de uma questão complexa que exige o envolvimento coletivo. Atualmente, um dos desafios em relação à construção e efetivação das políticas de trabalho e emprego direcionadas aos jovens se encontra na definição de qual é o melhor momento para que o jovem ingresse no mercado de trabalho. Afinal, a juventude 4 abarca uma multiplicidade de aspectos e experiências que são perceptíveis a partir de abordagens que tomam como referência o território, o contexto, o biológico e o psicológico. Por isso, essa definição ainda é um tema aberto e controverso.

A juventude constitui uma complexidade de situações que se expressam de diferentes formas na vida de cada jovem. Por isso, não é recomendável pensar em uma trajetória linear quando o assunto é educação e trabalho, cada jovem seguirá seu percurso conforme os determinantes sociais e culturais que está inserido. Portanto, é preciso que as políticas para a juventude sejam pensadas nesse sentido, respeitando as especificidades desse segmento, aliando suas necessidades a seus direitos.

Assim, o desafio está na dificuldade em se conceber um parâmetro etário que abarque este segmento. De acordo com o Conselho Nacional de Juventude (2006), a juventude compreende jovens com idade entre 15 e 29 anos. No entanto, a política também entende que o jovem percorre trajetórias diferenciadas que devem ser respeitadas e valorizadas. Desta forma, o jovem deve ser concebido a partir de sua construção social, cultural e histórica para uma melhor compreensão sobre suas particularidades, identidades, modos de agir e viver em sociedade, entre outros aspectos. Ao adentrar no universo juvenil é necessário ter em vista a heterogeneidade das experiências dos jovens em relação à escolarização e ao trabalho. Compreender essa diversidade é essencial para analisar tanto o momento em que se dá a inserção do jovem no mundo do trabalho, sua permanência e as implicações destas. Para Gonzalez (2012, p. 112): "a taxa de matrícula no ensino básico continua crescendo lentamente e parcela expressiva dos jovens não o completam antes de sair da escola. (...) Isto implica grandes diferenças quanto ao momento de entrada no mercado de trabalho segundo classe social".

A relação entre jovem, trabalho e educação perpassa especificidades inerentes à condição juvenil. Tanto a educação quanto o trabalho poderão ter significados diferentes para os jovens conforme o contexto em que estiverem inseridos. De acordo com o Conselho Nacional de Juventude (2006, p. 27-28): "Hoje o que se tem é uma perversa diferenciação entre jovens que podem combinar trabalhos criativos e educação de qualidade, e outros que, quando têm emprego e tentam perseguir alguma escolarização, têm que se engajar em trabalhos exaustivos que tolhem a possibilidade de dedicação a estudos mais reflexivos e críticos".

O Conselho Nacional de Juventude (2006) evidencia a importância de proporcionar aos jovens a garantia do trabalho digno e decente, pois muitas vezes esta garantia aparece em poucas iniciativas governamentais. Segundo o Conselho (2006, p. 27): “o chamado estágio continua sendo apenas um modo de as empresas acessarem mão de obra de relativa qualidade, a baixo custo, com muito pouco controle sobre o que esta atividade pode proporcionar ao jovem, em termos de formação e vivência profissional". Além disso, quase "inexistem discussões sobre a melhor forma de proporcionar emprego ao jovem de maneira a compatibilizar seus horários de trabalho com o estudo, tornando as duas atividades mais integradas".

No entanto, é fundamental considerar tais iniciativas, pois estas podem ter a capacidade de fazer grande diferença na formação social e profissional dos jovens. Na realidade, é necessário que estas e 
outras iniciativas sejam potencializadas no sentido de efetivar com qualidade as políticas de trabalho e emprego voltadas para os jovens:

É preciso mobilizar a sociedade para o debate acerca da implementação da legislação relativa ao trabalho juvenil e abrir novas linhas de ação nesse campo (...). O Estado deve também garantir segurança material para que a trajetória educacional do jovem não seja prejudicada pela necessidade de se garantir sobrevivência própria ou de seus familiares (CONSELHO NACIONAL DE JUVENTUDE, 2006, p. 27).

Deste modo, construir saídas para além destas ações poderá permitir que a centralidade na educação e no trabalho se configure mais fortemente como a grande solução. A relação jovem, trabalho e educação constitui um grande desafio para o Estado e a sociedade, embora já seja possível verificar certa evolução das políticas de trabalho e emprego voltadas aos jovens no âmbito do governo federal, sobretudo nos últimos anos, tomado por pano de fundo os problemas relativos à transição escola-trabalho e a questão do desemprego juvenil nas décadas de 1990 e 2000 (GONZALEZ, 2009). É importante registrar que a luta em busca do trabalho digno, decente e com qualidade vem crescendo, sobretudo, entre os jovens. A elaboração da Agenda Nacional do Trabalho Decente para a Juventude no Brasil representou um passo importante em direção à efetivação do direito ao trabalho. A partir de 2003, a promoção do Trabalho Decente foi assumida como compromisso pelo governo brasileiro e pela Organização Internacional do Trabalho. Esta "agenda reuniu um conjunto relevante de questões relacionadas à diversidade do trabalho juvenil em nosso país. Estimulou representantes de empregadores, sindicatos, governo e sociedade civil a construírem ações específicas para os jovens em relação ao mundo do trabalho" (CORROCHANO, 2011, p. 69). A efetivação dessas ações depende, principalmente, do envolvimento e do compromisso de diferentes atores, bem como a ampliação do diálogo com diferentes níveis de governo, entidades representativas dos trabalhadores e dos empresários, universidades, especialmente com diferentes organizações juvenis e com o conjunto da juventude brasileira (CORROCHANO, 2011). Ou seja, é fundamental que as ações no âmbito do trabalho sejam construídas coletivamente. No entanto, também é preciso ir além e compreender a "lógica de organização do capitalismo na contemporaneidade. Esse pressuposto exige situar os termos em que tais políticas operam quando estão em jogo novas formas de produção e reprodução da força de trabalho" (SILVA, 2012, p. 74).

Diante do exposto, é possível afirmar que as ações e iniciativas no âmbito do trabalho são decisivas para consolidar as políticas de trabalho e emprego no Brasil. Para tanto, urge o:

o reconhecimento de que os jovens são atores sociais e portadores de novas identidades coletivas, cabe desenvolver e implementar novos paradigmas sobre o trabalho de jovens: não se trata mais de trabalho como atenuante da pobreza ou alternativa à marginalidade e à exclusão. Trata-se do trabalho como direito e um componente essencial da formação do jovem, como indivíduo e cidadão (LEITE, 2003 apud CORROCHANO, 2011, p. 61).

\section{Considerações Finais}

A relação Estado-sociedade se constitui um desafio na contemporaneidade, principalmente quando se pensa na construção das políticas públicas brasileiras. É preciso considerar o contexto histórico e social, bem como o envolvimento de interesses conflitantes e contraditórios que permeiam a relação Estado-sociedade e políticas públicas.

No âmbito das políticas de trabalho e emprego voltadas aos jovens no Brasil constatou-se que muitos são os entraves na atualidade. De maneira geral, as ações e programas possuem uma atuação limitada em virtude das questões históricas presentes na estrutura da sociedade brasileira. Com isso, questiona-se até que ponto estas ações e programas contribuem para o processo de inserção dos jovens no mercado de trabalho, retirando-os da condição de desempregados e alterando, significativamente, o desemprego juvenil. Por esta ótica, o alcance e a efetividade das políticas de qualificação profissional na trajetória de trabalho dos jovens certamente não possuem soluções simples. Por outro lado, estas ações e programas, também são significativas, pois se configuram como requisitos essenciais da chamada empregabilidade, e portanto, estas políticas não devem ser desqualificadas sem antes considerarmos os diversos fatores e atores sociais que podem influenciar seu direcionamento. Nesse sentido, revela-se a relação dialética, ou seja, contraditória no trato das políticas públicas.

Quanto aos desafios, constatou-se a dificuldade em se conceber um parâmetro etário que abarque o segmento juvenil em razão de suas especificidades. Além disso, há o desafio de definir o melhor momento para o ingresso do jovem no mercado de trabalho, pois é necessário ter em vista a heterogeneidade das experiências 
dos jovens em relação à escolarização e ao trabalho. Cada jovem seguirá seu percurso conforme os determinantes sociais e culturais que está inserido. Assim, é preciso que as políticas para a juventude sejam concebidas com esse olhar, respeitando as particularidades desse segmento, aliando suas necessidades aos seus direitos. A relação dos jovens com o mundo do trabalho é bastante complexa e ocorre a partir de realidades distintas; as políticas de trabalho e emprego direcionadas a este segmento devem ser construídas preservando as especificidades que são inerentes à condição juvenil.

Esta reflexão pôde demonstrar que apesar de todas as dificuldades e impasses existentes na constituição e implementação das políticas de trabalho e emprego voltadas aos jovens, já é possível constatar certos avanços que devem ser potencializados. Um dos importantes avanços foi a criação do Departamento de Políticas de Trabalho e Emprego para a Juventude, em 2004, com o objetivo de atuar na promoção de trabalho, emprego e geração de renda para os jovens. Dentre os programas, ações e iniciativas voltadas para o público juvenil, destacam-se o Programa ProJovem Trabalhador, a Lei do Estágio (lei n. 11.788, de 25/09/2008) e a Aprendizagem. Ao se aproximar do universo juvenil logo se verifica o quanto o trabalho é importante e possui diferentes significados a partir da realidade de cada jovem. Compreender o porquê de sua busca por trabalho, por qualificação profissional, por uma colocação no mercado, e, tudo isso, em um contexto nada favorável, já se constitui como um grande desafio. Portanto, essa situação não requer soluções simples, é necessário o envolvimento e compromisso coletivo. Estado e sociedade precisam procurar caminhos que possibilitem a efetivação do direito ao trabalho com qualidade para o público juvenil.

\section{Referências}

ARAÚJO, A. V. Política pública, juventude e educação: o Programa Nacional de Inclusão de Jovens na perspectiva dos atores envolvidos. 2011. 242 f. Tese (Doutorado em Educação) - Programa de Pós-Graduação em Educação, Universidade Federal de Pernambuco - UFPE, Recife - PE, 2011.

BOURDIEU, P. A juventude é apenas uma palavra? In: Questões de Sociologia. Tradução: Miguel Serras Pereira. Lisboa: Fim de Século, 2003.

BRASIL. Ministério da Educação - MEC. Programa Nacional de Acesso ao Ensino Técnico e Emprego: Pronatec. 2014. Disponível em: <http://portal.mec.gov.br/pronatec>. Acesso em: 15 mai. 2014.

. Ministério do Trabalho e Emprego - MTE. Políticas de Juventude. 2014a. Disponível em: <http://acesso.mte.gov.br/politicas juventude/>. Acesso em: 15 mai. 2014.

CONSELHO NACIONAL DE JUVENTUDE. Política Nacional de Juventude: diretrizes e perspectivas. São Paulo: Fundação Friedrich Ebert, 2006.

CORROCHANO, M. C. Trabalho e Educação no tempo da juventude: entre dados e ações públicas no Brasil. In: PAPA, F. de C.; FREITAS, M. V. (Orgs.). Juventude em pauta: políticas públicas no Brasil. São Paulo: Petrópolis, p. 45-72, 2011.

GONZALEZ, R. Políticas de emprego para jovens: entrar no mercado de trabalho é a saída? In: CASTRO, J. A. de; AQUINO, L. M. C. de; COELHO, C. (Orgs.). Juventudes e Políticas Sociais no Brasil. Brasília: IPEA, p. 109-128, 2009.

HARVEY, D. Condição Pós-Moderna. São Paulo: Edições Loyola, 1992.

HOFLING, E. de M. Estado e Políticas (Públicas) Sociais. Cadernos Cedes. São Paulo, v. 21, n. 55, p. 30-41, nov. 2001.

OIT. Organização Internacional do Trabalho. Trabajo Decente y Juventud: Políticas para la acción. 2013. Disponível em: <http:// www.oitcinterfor.org/node/5464>. Acesso em: 15 mai. 2014.

PEREIRA, P. A. P. Discussões conceituais sobre política social como política pública e direito de cidadania. In: BOSCHETTI, I.; BEHRING, E. R.; SANTOS, S. M. M.; MIOTO, R. C.T.(orgs). Política Social no Capitalismo: tendências contemporâneas. São Paulo: Cortez, 2009.

PINTO, G. A. A organização do trabalho no século 20: taylorismo, fordismo e toyotismo. São Paulo: Expressão Popular, 2013.

POCHMANN, M. A batalha pelo primeiro emprego: as expectativas e a situação atual do jovem no mercado de trabalho. São Paulo: Publisher Brasil, 2000.

REZENDE, F. C. Por que falham as Reformas Administrativas? Rio de Janeiro: FGV, 2004.

SERAFIM, M. P.; DIAS, R. B. Conceitos e ferramentas para análise de política pública. In: BENINI, E. et al (orgs.). Gestão Pública e Trabalho Associado: fundamentos e perspectivas. São Paulo: Outras Expressões, 2011.

SILVA, M. M. Na onda da flexibilidade: a experiência do desemprego vista pelo recorte geracional e de qualificação profissional. In: Jovens, Trabalho e Educação: a conexão subalterna de formação para o capital. Campinas, SP: Mercado das letras, 2012.

SOUZA, C. Estado de arte da pesquisa em Políticas públicas. In: HOCHMAM, G.; ARRETCHE, M.; MARQUES, E. (Orgs.). Políticas Públicas no Brasil. Rio de janeiro: FIOCRUZ, 2007.

TEIXEIRA, R. C. F. A passagem do "direito ao trabalho" para a "empregabilidade": privatização do espaço público através das políticas sociais de emprego na contemporaneidade. In: Revista Unimontes Científica. V. 5, ano 1, 2003. Disponível em: <http:// www.ruc.unimontes.br/index.php/unicientifica/article/view/56/50>. Acesso em: 15 mai. 2014. 
VELASCO, E. G. Juventudes e políticas públicas de trabalho no Brasil: a qualificação profissional e a tensão entre preferência e individualização. In: SILVA, M. O. da S.; Yazbek, M. C. Políticas Públicas de Trabalho e Renda no Brasil Contemporâneo. São Paulo: Cortez, 2012.

\section{Notas}

1 Serviço Nacional de Aprendizagem Industrial (SENAI), Serviço Nacional deAprendizagem Comercial (SENAC), Serviço Nacional de Aprendizagem Rural (SENAR), Serviço Nacional de Aprendizagem do Transporte (SENAT).

2 No conceito de empregabilidade está implícita a tendência em eximir o Estado do seu dever em relação ao direito do cidadão ao trabalho, de caráter público e político, e repassar tal dever aos indivíduos, considerados isoladamente, tornando esse dever, deste modo, uma questão privada, pessoal. Assim, a empregabilidade significa o dever de cada indivíduo (que desaparece como cidadão, já que, no conceito de cidadania, há a dimensão do coletivo, do público) de encontrar seu próprio trabalho no mercado capitalista (TEIXEIRA, 2003).

3 Ao ser incorporado pelas economias periféricas como modelo de desenvolvimento político, econômico e social, este resultou num agravamento das crises já preexistentes. No Brasil culminou na implantação da doutrina neoliberal no Estado na década de 1990, persistindo até os dias atuais, impondo à classe trabalhadora, de um lado, a precarização dos serviços públicos e flexibilização dos seus direitos, mediante o aumento da informalidade e do desemprego estrutural; ao empresário nacional, de outro, uma posição subalterna na divisão internacional do trabalho, com a manutenção de acordos predatórios fundados em políticas monetárias, ditadas por organismos de controle financeiro internacionais (PINTO, 2013).

4 Este trabalho utiliza o conceito de juventudes, pois para Bourdieu (2003, p. 152-153), juventude é um construto social e histórico, ou, dito em sua maneira radical, "a 'juventude' é apenas uma palavra, e que o fato de falar dos jovens como se fossem uma unidade social, um grupo constituído, dotado de interesses comuns, e relacionar estes interesses a uma idade definida biologicamente já constitui uma manipulação evidente".

\section{Cristiane Bonfim Fernandez}

cristianebf@yahoo.com.br

Doutora em Política Social pela Universidade de Brasília (UnB)

Professora adjunta do Departamento de Serviço Social da Universidade Federal do Amazonas (UFAM), vinculada ao Grupo de Estudos e Pesquisas em Processo de Trabalho e Serviço Social (GETRA).

\section{Maisa Bruna de Almeida Nunes}

maisabruna@hotmail.com

Mestre em Serviço Social e Sustentabilidade na Amazônia pela Universidade Federal do Amazonas (UFAM). Pesquisadora vinculada ao Grupo de Estudos e Pesquisas em Processo de Trabalho e Serviço Social (GETRA).

\section{UFAM}

Avenida General Rodrigo Octávio, 6200 - Coroado I.

Manaus - Amazonas - Brasil

CEP: 69077-000 